\title{
HOW TO COMPARE THE ABSOLUTE VALUES OF OPERATOR SUMS AND THE SUMS OF ABSOLUTE VALUES?
}

\author{
EUN-YOUNG LEE
}

Abstract. We address the problem of comparing $|A+B|$ and $|A|+|B|$, for $A, B \in \mathbb{M}_{n}(\mathbb{C})$. Some results are obtained by using a technique of positive linear maps and several open questions are proposed.

Mathematics subject classification (2010): Primary 15A60, 47A30, 47A60.

Keywords and phrases: Symmetric norms, operator inequalities, concave functions.

\section{REFERENCES}

[1] K. AUdENAERT, Variance bounds with an application to norm bounds for commutators, Linear Algebra Appl. 432 (2010), 1126-1143.

[2] R. Bhatia, Matrix Analysis, Springer, 1997, New-York.

[3] R. Bhatia, Positive definite matrices, Princeton University Press.

[4] A. BÖTTCHER AND D. WenZEL, How big can the commutator of two matrices be and how big is it typically?, Linear Algebra Appl. 403 (2005), 216-218.

[5] A. BötTCher And D. WenZel, The Frobenius norm and the commutator, Linear Algebra Appl. 429 (2008), 1864-1885.

[6] J.-C. Bourin, Symmetric norms and reverse inequalities to Davis and Hansen-Pedersen characterizations of operator convexity, Math. Inequal. Appl. 9, 1 (2006), 33-42.

[7] J.-C. Bourin, A matrix subadditivity inequality for symmetric norms, Proc. Amer. Math. Soc. 138 (2010), 495-504.

[8] J.-C. Bourin And E. RiCARD, An asymmetric Kadison's inequality, Linear Alg. Appl. 433 (2010), 499-510.

[9] J.-C. BOURIN AND M. UCHIYAMA, A matrix subadditivity inequality for $f(A+B)$ and $f(A)+f(B)$, Linear Alg. Appl. 423 (2007), 512-518.

[10] E-Y. LEE, A matrix reverse Cauchy-Schwarz inequality, Linear Alg. Appl. 430 (2009), 805-810.

[11] E-Y. LEE, Rotfel'd type inequalities for norms, Linear Algebra Appl. 433 (2010), 580-584.

[12] R.C. Thompson, Convex and concave functions of singular values of matrix sums, Pacific J. Math. 66 (1976), 285-290. 